\title{
LA ELABORACIÓN DE CUENTAS CON VALVAS DE MOLUSCOS EN PATAGONIA A TRAVÉS DE LA ARQUEOLOGÍA EXPERIMENTAL.
}

\section{SHELL BEAD PRODUCTION IN PATAGONIA THROUGH EXPERIMENTAL ARCHEOLOGY.}

\author{
Sabrina Leonard $\mathrm{t}^{1}$ \\ ${ }^{1}$ Consejo Nacional de Investigaciones Científicas y Técnicas (CONICET) - Instituto \\ Nacional de Antropología y Pensamiento Latinoamericano (INAPL). 3 de Febrero 1378 \\ CABA. sabrinaleonardt@yahoo.com.ar
}

Presentado: 30/11/2018 - Aceptado: 16/04/2019

\begin{abstract}
Resumen
En este trabajo se presentan los resultados de un programa de arqueología experimental de elaboración de cuentas de valva, llevado a cabo en el marco de un proyecto de investigación doctoral cuyo objetivo fue analizar los patrones de producción y distribución de este tipo de artefactos en Patagonia durante el Holoceno tardío. El programa experimental se desarrolló con la finalidad de conocer: la factibilidad de generar diferentes diseños métrico-morfológicos de cuentas empleando valvas de distintos moluscos marinos, el tiempo y grado de habilidad necesarios para elaborarlos, y profundizar en el conocimiento de los tipos de huellas técnicas generadas durante su producción, a fin de construir un marco de referencia que permita reconocer instancias de producción local en el registro arqueológico. Los resultados permiten sugerir que no existen importantes limitaciones relacionadas con las cualidades de las materias primas ni con el grado de conocimiento técnico necesario para elaborar estos tipos de cuentas, pudiendo ser llevadas a cabo con relativa facilidad por un operador poco experto. Asimismo, se propone que la posibilidad de reconocer contextos de producción de cuentas estará limitada por la identificación de unas pocas piezas con huellas diagnósticas.
\end{abstract}

Palabras clave: cuentas de valva, experimentación, comunicación visual, Patagonia

\begin{abstract}
This paper presents the results of an experimental archeology program of shell bead production, carried out within the framework of a Ph.D. research project whose goal was to analyze the production and distribution pattern of these artifacts in Patagonia during Late Holocene. The goal of experimental program it was knowing: the requirements to generate metrics and morphological variability of shell beads using different marine mollusks; the time and degree of skill necessary to elaborate them; and deepen in the knowledge of the technical traces generated during their production, in order to build a frame of reference that allows to recognize instances of local production in the archaeological record. The results suggest that there are no important limitations related to the qualities of raw materials or the degree of knowhow necessary to develop these types of shell beads, and can be carried out with relative ease by a low-skilled operator. It is also proposed that the possibility of recognizing shell beads production contexts will be limited by the identification of a few pieces with diagnostic fingerprints.
\end{abstract}


Key words: shell beads, experimental archaeology, visual communication, Patagonia

\section{Introducción}

Los objetos de adorno colgantes, entendidos como aquellos artefactos, generalmente de tamaño pequeño, y con orificios o incisiones que les permiten ser colgados o sujetados al cuerpo, vestimenta u otros, son el tipo de artefacto de adorno corporal con más frecuencia recuperado en el registro arqueológico a escala mundial desde el Paleolítico (Álvarez Fernández 2006). Al igual que otras formas de decoración del cuerpo (p. ej. tatuajes, escarificaciones, pintura corporal, etc.), estos artefactos tienen como característica distintiva estar elaborados con el fin expreso de ser vistos y, en tal sentido, constituyen medios de comunicación visual (Kuhn y Stiner 2007). La etnografía informa respecto de su participación activa en la construcción de relaciones sociales, funcionando como vías para la transmisión de información entre personas y/o grupos, comunicando mensajes relacionados con estados particulares del portador ( $\mathrm{p}$. ej. edad, disponibilidad para el matrimonio, estatus, riqueza o habilidad, véase Wiessner 1984, Graeber 1996, entre otros), así como expresando información relacionada con valores o creencias sociales, afiliación grupal o etnicidad (Wobst 1977, Wiessner 1984, entre otros).

Si bien es claro que arqueológicamente no es posible acceder al contenido explícito de lo que expresaron estos artefactos como mensaje en el pasado, ya que el mismo solo es inteligible en un contexto sistémico, sí es posible abordar los contenidos implícitos que pautaron su producción social a partir del análisis de las características relacionadas con su diseño, producción y uso (véase Kuhn y Stiner 2007, Stiner 2014). Partiendo del empleo de la experimentación como una herramienta metodológica que permite construir un puente entre lo observado en el registro arqueológico y los hechos no observados del contexto sistémico (Binford 1981), en este trabajo se presenta una aproximación desde dicha metodología al análisis de las características de la producción de cuentas de valva en Patagonia durante el Holoceno tardío.

\section{Cuentas de valva en Patagonia}

Las cuentas, principalmente elaboradas sobre valvas de moluscos, son los artefactos de adorno corporal usualmente recuperados en el registro arqueológico de Patagonia para los últimos 4000 años AP. Éstas suelen hallarse tanto en contextos habitacionales -asociadas a distinto tipo de actividades- así como también formando parte del acompañamiento mortuorio en enterratorios (véase Zubimendi 2010, Leonardt 2016a). Generalmente poseen tamaño pequeño y formas circulares, aunque también se registran otras morfologías (p. ej. rectangular, oval, campaniforme, automorfas, véase Gómez Otero 2007, Zubimendi 2008, Leonardt 2014, 2016a, 2016b, entre otros). Si bien la identificación del taxón empleado para su elaboración suele ser compleja debido al intenso grado de formatización que presentan, en algunos casos se ha podido reconocer el uso de especies marinas (p. ej. Aulacomya atra, Fissurella sp., Veneridae, Volutidae, véase Prates 2008, Zubimendi 2008, Leonardt 2014, 2016b, entre otros) y de agua dulce (Diplodon chilensis patagonicus, Cassiodoro 2005, Prates 2008). 
En las últimas décadas varios investigadores han abordado el análisis de este tipo de registro material con distinto énfasis e intereses. La amplia distribución espacial de cuentas y valvas de moluscos marinos en Patagonia ha llevado a interrogarse respecto de su participación en las redes de circulación de materiales que caracterizan al Holoceno tardío en la región, resaltando su potencial como indicador de interacción (Silveira et al. 2010, Zubimendi y Ambrústolo 2011, Cimino y Pastorino 2018, entre otros). Asimismo, su presencia en contextos mortuorios ha permitido explorar la relación con el registro funerario en términos de diferencias de sexo y edad (Cassiodoro y García Guraieb 2009) y discutir su rol como señaladores de estatus o etnicidad (Gómez Otero 2007, Della Negra e Ibáñez Saint Paul 2012, entre otros). En otros casos, los análisis se han centrado en la caracterización métrico-morfológica de las cuentas apuntando a discutir aspectos relacionados con la existencia de patrones estandarizados (Leonardt 2016b, Cardillo y Borella 2017), o a evaluar la presencia de tendencias temporales y/o regionales (Fernández y Ramos 2008, Leonardt 2016a). Algunos investigadores también han considerado el análisis de los procesos de manufactura de estos artefactos. El principal antecedente de este tipo de abordaje lo constituye, aunque para el sur de la provincia de La Pampa, los trabajos realizados por Cimino sobre el conjunto arqueomalacológico del sitio Chenque 1 (Cimino 2004, 2007). En estos trabajos se indaga respecto de los procesos de manufactura empleados para elaborar las cuentas a partir del análisis minucioso de las piezas y sus huellas técnicas, estableciendo las posibles cadenas operativas implicadas en su producción. Asimismo, Fernández y Ramos (2008) y Prates (2008) han propuesto situaciones de producción local de cuentas (con valvas de moluscos de distribución local y alóctona) en sitios arqueológicos de la provincia de Río Negro, en función de las características técnicas y morfológicas de los materiales hallados (Fernández y Ramos 2008, Prates 2008) y su asociación con posibles herramientas empleadas para su elaboración, tales como un perforador lítico de obsidiana (Fernández y Ramos 2008). Incluso, sobre la base de las características morfológicas y abundancia de cuentas de valva, en el área costera del noroeste de Chubut se ha propuesto que, hacia los últimos ca. 750 años $\mathrm{AP}$, se habría producido un perfeccionamiento en la producción de cuentas de valva que habría permitido sostener la existencia de artesanos especializados que habrían dedicado parte del tiempo en su producción y la posibilidad del uso de estos artefactos como bienes de intercambio exclusivos de la costa (Gómez Otero 2007).

Sólo recientemente se ha comenzado a abordar el análisis de estos artefactos de manera sistemática desde la arqueología experimental, buscando generar criterios unificados para el análisis de estos restos materiales y apuntando a discutir las implicancias sociales de su producción. En este sentido, las primeras experiencias de elaboración de cuentas con valvas del molusco de agua dulce Diplodon chilensis (Leonardt 2013, 2014) han contribuido a generar un acercamiento inicial a estos aspectos, a partir de evaluar la aplicabilidad de distintas técnicas e instrumentos comúnmente asumidos en su elaboración y de la construcción de un marco de referencia para identificar desechos y subproductos de manufactura de cuentas que permita reconocer situaciones de producción local (Leonardt 2013, 2014). 
El objetivo de este trabajo es presentar los resultados de un programa experimental de elaboración de cuentas de valva realizado para indagar sobre distintos aspectos prácticos de su producción. El mismo constituye una ampliación del realizado inicialmente en 2013 con valvas de Diplodon chilensis y forma parte de una investigación doctoral orientada a analizar los patrones de producción y distribución de cuentas de valva en Patagonia continental, a fin de evaluar su papel como parte de un código visual compartido a escala macroregional durante el tramo final del Holoceno tardío (Leonardt 2017). Se presenta la información resultante de experiencias de elaboración de cuentas de diferentes morfologías y tamaños, empleando distintas especies de moluscos marinos e incorporando dos técnicas no implementadas anteriormente para la formatización de las piezas: talla por presión y percusión directa sobre yunque. Los resultados se discuten en términos del papel que pudieron desempeñar las cuentas -y los artefactos elaborados con ellas- como medios de comunicación visual en el pasado.

\section{Encuadre teórico y objetivos del programa experimental}

En sociedades de cazadores-recolectores la comunicación visual a través de objetos es un mecanismo comúnmente utilizado para crear y sostener relaciones sociales a larga distancia (Wobst 1977, Wiessner 1984, entre otros). Podemos definir a la comunicación como la transmisión de información entre un emisor y un receptor. En este proceso, el emisor codifica el mensaje que desea transmitir en una señal (p. ej. sonidos, palabras) que es enviada a través de un canal de comunicación (p. ej. aire, carta) y que deberá ser decodificada e interpretada por el receptor. Por lo tanto, para que la comunicación sea posible, es necesario que el código en el que se transmite el mensaje sea compartido por ambos (Shannon y Weaver 1964). Cuando se habla de comunicación mediada por objetos, la información está codificada en las características visuales de los artefactos tales como la forma, la materia, el color, el diseño, etc. (Wobst 1977, Eco 1986 [1968], entre otros). En este caso, el emisor puede producir el mensaje en ausencia del receptor y este último puede recibirlo sin la presencia física del emisor, incluso sin conocerlo personalmente (Wobst 1977). No obstante, es necesario que existan ciertas convenciones respecto de cuáles son los rasgos del objeto que se deben destacar a fin de que los observadores puedan reconocer las formas percibidas y extraer, interpretar y entender la información transmitida a través del objeto (Wobst 1977, Eco 1986 [1968], entre otros).

Las cuentas, particularmente, son elementos estandarizables en términos del diseño de cada una de las unidades pero que a su vez permiten una gran variabilidad de combinaciones, tanto en relación con los distintos tipos de objetos que se pueden elaborar con ellas (collares, pulseras, tocados, aplicaciones a la vestimenta, etc.) como respecto de los diseños que pueden presentar dichos objetos (véase Wiessner 1984, Kuhn y Stiner 2007). Por ello, tienen un valor comunicativo que depende tanto de las unidades en sí mismas, en relación con las características de su forma, superficie, materia prima, color, etc., como de la disposición y combinaciones que se hagan con ellas (Wiessner 1984, Stiner 2014). 
Arqueológicamente, la posibilidad de evaluar si las cuentas formaron parte de un código visual compartido a escala macroregional en Patagonia requiere, como mínimo, identificar la existencia de patrones de diseño y producción estandarizados de estos artefactos -en tanto unidades mínimas de comunicación- en conjuntos arqueológicos de distintas zonas de Patagonia, que puedan informar respecto de la existencia de cánones sociales compartidos (Stiner 2014), y reconocer distintos contextos de producción local, dado que es necesario que el código sea replicable (véase Stiner 2014). En este marco, el programa experimental se realizó con el propósito de generar información empírica que permita conocer las características técnicas y prácticas de la producción de cuentas. Específicamente tuvo tres objetivos: a) evaluar la posibilidad de producir variabilidad métricomorfológica con valvas de distintas especies de moluscos, a fin de conocer en qué medida es factible que los diseños de las cuentas registradas arqueológicamente sean producto de las elecciones hechas por los artesanos y no de limitaciones impuestas por las técnicas, herramientas o materias primas; b) conocer el grado de pericia y tiempo necesarios para su elaboración, a fin de evaluar la posibilidad de replicabilidad del código y c) profundizar el conocimiento de la cadena operativa de producción de estos artefactos a fin de contribuir a la elaboración de un marco de referencia para la identificación de huellas técnicas y desechos de manufactura que permita reconocer situaciones de producción local.

Se parte del concepto de cadena operativa, el cual alude a un conjunto de operaciones que transforman a un material de su estado natural (original) a un estado elaborado (Cresswell 1976 en Lemonnier 1986). En un sistema tecnológico se ponen en juego materiales, secuencias de acción, herramientas (dentro de las cuales se incluye el propio cuerpo) y habilidades cognitivas (Lemonnier 1986). Estas últimas son de dos tipos: el conocimiento teórico (knowledge), que refiere a los modelos mentales de los que dispone un individuo y la capacidad de enlazar de manera abstracta los pasos necesarios para llevar a cabo una actividad tecnológica, y el "saber hacer" (know-how), es decir, el conocimiento práctico que surge de la experiencia de llevar a cabo la acción confrontando la habilidad personal con las materias primas y herramientas empleadas (Apel 2008). Así, la consecución exitosa de una cadena operativa estará condicionada tanto por las limitaciones que puedan imponer ciertos factores extrasomáticos tales como las características de la materia prima disponible o las condiciones de acceso a las mismas, así como también por el grado de complejidad del conocimiento técnico (know-how) necesario para conseguir el resultado deseado (Lemonnier 1986, Apel 2008). Asimismo, durante la confección de un artefacto se desarrollan una serie de acciones o gestos que producen diferentes restos materiales que son diagnósticos de esa acción. A partir del reconocimiento de esos rasgos es posible reconstruir la sucesión de acciones llevadas a cabo en la elaboración del mismo (Apel 2008). 


\section{Materiales y métodos}

Partiendo de las consideraciones teóricas antes mencionadas, de los resultados obtenidos inicialmente en Leonardt $(2013,2014)$ y de los lineamientos metodológicos propuestos por distintos autores (Suárez Diez 2002 [1975], Laporte et al. 1994, Velázquez Castro 2007, entre otros), se diseñó una cadena operativa compuesta de tres etapas organizadas en la siguiente secuencia fija: a) extracción de la forma-base, b) formatización destinada a la obtención de una preforma y c) perforación de la pieza. A partir de esta secuencia se elaboraron dos tipos morfológicos de cuentas de valva: cuentas de contorno circular/sub-circular (en adelante C/SCI) y cuentas de contorno sub-cuadrangular/sub-rectangular (en adelante SCD/SR). A su vez, para cada tipo morfológico se realizaron dos variantes de tamaño clasificadas en pequeñas (entre $10 \mathrm{y}$ $18 \mathrm{~mm}$ de diámetro y entre 10 y $18 \mathrm{~mm}$ de lado, respectivamente) y grandes (entre $20 \mathrm{y}$ $38 \mathrm{~mm}$ de diámetro y entre 20 y $29 \mathrm{~mm}$ de lado, respectivamente). Cada uno de estos tipos de cuentas se elaboró empleando las valvas de cuatro taxones de moluscos marinos: Aulacomya atra (Molina 1782), Nacella magellanica (Gmelin 1791) y almejas de la familia Veneridae, estas últimas correspondientes tanto a ejemplares enteros de Euromalea exalbida (Dillwyn 1817) y Leukoma antiqua (King 1832), como a fragmentos rodados. En todos los casos se trata de especies de registro frecuente en los sitios arqueológicos de Patagonia continental (véase Zubimendi 2010, 2015). Los ejemplares fueron recolectados muertos ${ }^{1}$, en su mayoría, en la ciudad de Puerto Madryn (costa del golfo Nuevo, norte de Chubut), pero también se emplearon valvas de Aulacomya atra y Nacella magellanica procedentes de Punta Entrada y Punta Loyola (costa sur de Santa Cruz). En todos los casos se utilizaron como herramientas artefactos de registro frecuente en los contextos arqueológicos de Patagonia, tales como percutores, lascas, artefactos de filo formatizado y perforadores líticos de sílice y calcedonia (véase por ejemplo Prates 2008, Palacios 2008), así como lajas de granito como superficies abrasivas.

Cada cuenta se manufacturó de manera individual siguiendo la cadena operativa antes mencionada. Durante el proceso experimental se llevó registro escrito y fotográfico de las operaciones realizadas, sus características, los tiempos requeridos y se evaluó el ajuste de las técnicas empleadas con cada tipo de valva para lograr las cuentas de las formas y tamaños deseados. Asimismo, se registraron las características de los subproductos y desechos producidos en cada etapa de manufactura y las huellas diagnósticas generadas por las distintas técnicas, cotejándolas con los resultados obtenidos en la elaboración de cuentas con valvas de Diplodon chilensis (Leonardt 2013). A continuación, se detallan las características de las etapas experimentales.

a) Extracción de la forma-base. Consiste en la extracción de una o varias formas-base a partir de una valva. Este procedimiento se llevó a cabo mediante la técnica de percusión directa (Suárez Diez 2002[1975], Laporte et al. 1994, Leonardt 2013, 2014, entre otros), para lo cual se utilizó un percutor lítico. 
b) Formatización. Refiere al proceso de regularización del contorno de la cuenta a fin de lograr la forma deseada, en este caso, un fragmento de valva plano y de contorno C/SCI o SCD/SR. Esta actividad se llevó a cabo aplicando distintas técnicas según el caso: corte seguido de presión (véase Velázquez Castro 2007, Leonardt 2013, 2014), percusión directa sobre yunque (Mayo Torné 2004), talla mediante presión (Suárez Diez 2002[1975], Mayo y Cooke 2005) y abrasión (Suárez Diez 2002[1975], Laporte et al. 1994, Velázquez Castro 2007, Leonardt 2013, 2014, entre otros). Para realizar la técnica de corte seguido de presión se emplearon lascas y artefactos líticos de filo formatizado, en la percusión directa sobre yunque se usaron percutores líticos como instrumento activo y lajas de granito a modo de yunque, mientras que para la talla mediante presión se usaron lascas de calcedonia y sílice. Por último, para llevar a cabo el proceso de abrasión se emplearon guijarros de río y lajas de granito.

c) Perforación. Esta etapa tiene por objetivo generar un orificio de suspensión. Se empleó, en todos los casos, técnica de desgaste por rotación. Esta técnica refiere a la acción de rotar de manera alterna un instrumento afilado sobre la superficie de la valva a fin de producir orificios circulares (Suárez Diez 2002[1975], Laporte et al. 1994, Velázquez Castro 2007, Leonardt 2013, 2014, entre otros). Para ello se usaron perforadores líticos de calcedonia y sílice sin enmangue.

Las piezas y los desechos generados en las distintas etapas de manufactura fueron analizados, a ojo desnudo y con bajos aumentos (lupa de mano y lupa binocular a 10x, 20x y 40x), siguiendo los criterios propuestos en Leonardt $(2013,2014)$. Para cada técnica aplicada y tipo de valva empleado se registró:

a) Tipos de formas-base y fragmentos formatizados. Implicó la consideración de las características generales (formas, tamaños, cantidad de trozos útiles por valva, etc.) y huellas técnicas visibles en los fragmentos producidos durante la extracción de las formas-base y en las preformas producidas durante la etapa de formatización.

b) Tipos de fragmentos descartados. Se consideraron las características generales (formas y tamaños) y anatómicas de los fragmentos descartados para cada tipo de valva durante el proceso de elaboración y la presencia/ausencia de huellas técnicas.

c) Características de las cuentas terminadas. Se registraron las características generales de las cuentas terminadas (tamaño, espesor, diámetro de la perforación) y las huellas técnicas presentes en las mismas.

\section{Resultados}

Se realizaron 68 experiencias de producción, de las cuales 22 (32\%) fracasaron, resultando un total de 46 cuentas: 29 de morfología C/SCI (siete grandes y 22 pequeñas, Tabla 1) y 17 de morfología SCD/SR (siete grandes y 10 pequeñas, Tabla 2). A continuación se describen las características del proceso experimental. 


\begin{tabular}{|c|c|c|c|c|c|c|c|c|c|c|c|}
\hline \multirow{3}{*}{ Exp. } & \multirow{3}{*}{$\begin{array}{l}\text { Cat. } \\
\text { Tam. }\end{array}$} & \multirow{3}{*}{ Éxito } & \multirow{3}{*}{ Taxón } & \multicolumn{5}{|c|}{ Operaciones y tiempos por técnicas } & \multirow{2}{*}{\multicolumn{3}{|c|}{ Medidas }} \\
\hline & & & & \multirow{2}{*}{$\begin{array}{l}\text { EFB } \\
\text { PD }\end{array}$} & \multicolumn{3}{|c|}{ Formatización } & \multirow{2}{*}{$\begin{array}{c}\text { Perfo. } \\
\text { DPR } \\
\end{array}$} & & & \\
\hline & & & & & PDSY & $\mathrm{Ab}$ & TPP & & D & E & DP \\
\hline 1 & $P$ & SI & A. atra & n.t. & 2,3 & $5,5^{\prime}$ & - & 7 & 11,5 & 1,5 & 2 \\
\hline 2 & $\mathrm{P}$ & SI & A. atra & n.t. & 2 & 5,2 & - & 8 & 12 & 2 & 2,5 \\
\hline 3 & $\mathrm{P}$ & SI & A. atra & n.t. & $2^{\prime}$ & $8,1^{\prime}$ & - & $6^{\prime}$ & 12 & 1,5 & 2 \\
\hline 4 & $P$ & NO & A. atra & n.t. & ROTA & - & - & - & - & - & - \\
\hline 5 & $\mathrm{P}$ & SI & A. atra & n.t. & $1,9^{\prime}$ & 3 & - & $14^{\prime}$ & 11 & 1,2 & 1,5 \\
\hline 6 & $P$ & SI & A. atra & n.t. & 2 & $2,6^{\prime}$ & - & $6^{\prime}$ & 13,5 & 1 & 3 \\
\hline 7 & $P$ & SI & A. atra & n.t. & $1,5^{\prime}$ & 2 & - & $10^{\prime}$ & 12 & 2 & 2 \\
\hline 8 & $\mathrm{P}$ & SI & A. atra & n.t. & $1^{\prime}$ & 3 & - & 8 & 12 & 1 & 3 \\
\hline 9 & $P$ & SI & A. atra & n.t. & $1,8^{\prime}$ & $2,8^{\prime}$ & - & $9^{\prime}$ & 10 & 1 & 1,2 \\
\hline 10 & $\mathrm{P}$ & NO & A. atra & n.t. & ROTA & - & - & - & - & - & - \\
\hline 11 & $\mathrm{P}$ & SI & Veneridae & n.t. & $1^{\prime}$ & $3,1^{\prime}$ & - & 7 & 16,7 & 3,1 & 2 \\
\hline 12 & $\mathrm{P}$ & SI & Veneridae & n.t. & $1^{\prime}$ & $1,5^{\prime}$ & - & $6^{\prime}$ & 13,5 & 2,9 & 2 \\
\hline 13 & $\mathrm{P}$ & SI & Veneridae & n.t. & 2 & $2,4^{\prime}$ & - & 5 & 15 & 2,9 & 2 \\
\hline 14 & $P$ & SI & Veneridae & n.t. & $1^{\prime}$ & $2,3^{\prime}$ & - & $11^{\prime}$ & 14,6 & 3,2 & 3 \\
\hline 15 & $\mathrm{P}$ & SI & Veneridae & n.t. & $1,5^{\prime}$ & $2,1^{\prime}$ & - & $7^{\prime}$ & 14 & 3,2 & 1,5 \\
\hline 16 & $P$ & SI & N. magellanica & n.t. & $2,1^{\prime}$ & 3 & - & $5^{\prime}$ & 10 & 1,3 & 2 \\
\hline 17 & $P$ & NO & N. magellanica & n.t. & ROTA & - & - & - & - & - & - \\
\hline 18 & $\mathrm{P}$ & SI & N. magellanica & n.t. & 2 & $0,6^{\prime}$ & - & $4^{\prime}$ & 14 & 1,5 & 1,5 \\
\hline 19 & $P$ & SI & N. magellanica & n.t. & $2^{\prime}$ & $2,2^{\prime}$ & - & $6^{\prime}$ & 17,5 & 1,2 & 2 \\
\hline 20 & $\mathrm{P}$ & SI & Veneridae (ro) & - & - & - & $2,5^{\prime}$ & $9^{\prime}$ & 11 & 2 & 2 \\
\hline 21 & $\mathrm{P}$ & SI & Veneridae (ro) & - & - & - & $3^{\prime}$ & $6^{\prime}$ & 11 & 2 & 2,5 \\
\hline 22 & $\mathrm{P}$ & SI & Veneridae (ro) & - & - & - & $1,5^{\prime}$ & 5 & 11 & 1,5 & 3 \\
\hline 23 & $\mathrm{P}$ & SI & Veneridae (ro) & - & - & - & $3,2^{\prime}$ & 5 & 13 & 2 & 3 \\
\hline 24 & $\mathrm{P}$ & NO & Veneridae (ro) & - & - & - & ROTA & - & - & - & - \\
\hline 25 & $\mathrm{P}$ & NO & Veneridae (ro) & - & - & - & ROTA & - & - & - & - \\
\hline 26 & $\mathrm{P}$ & SI & Veneridae (ro) & - & - & - & $2,2^{\prime}$ & 4 & 12 & 2 & 2 \\
\hline 27 & $\mathrm{P}$ & SI & Veneridae (ro) & - & - & - & 3. & $6^{\prime}$ & 12 & 2 & 1,5 \\
\hline 28 & $\mathrm{P}$ & NO & Veneridae (ro) & - & - & - & ROTA & - & - & - & - \\
\hline 29 & $\mathrm{P}$ & NO & A. atra & - & - & - & ROTA & - & - & - & - \\
\hline 30 & $P$ & NO & A. atra & - & - & - & ROTA & - & - & - & - \\
\hline 31 & $\mathrm{P}$ & NO & A. atra & - & - & - & ROTA & - & - & - & - \\
\hline 32 & $\mathrm{P}$ & NO & N. magellanica & - & - & - & ROTA & - & - & - & - \\
\hline 33 & $\mathrm{P}$ & NO & N. magellanica & - & - & - & ROTA & - & - & - & - \\
\hline 34 & G & NO & A. atra & n.t. & $2,5^{\prime}$ & ROTA & - & - & - & - & - \\
\hline 35 & G & SI & A. atra & n.t. & $4^{\prime}$ & $19,4^{\prime}$ & - & $8^{\prime}$ & 38 & 2 & 1 \\
\hline 36 & G & NO & A. atra & ROTA & - & - & - & - & - & - & - \\
\hline 37 & G & SI & A. atra & n.t. & $2,2^{\prime}$ & 3 & - & $10^{\circ}$ & 26 & 1,5 & 2 \\
\hline 38 & G & SI & A. atra & n.t. & $1^{\prime}$ & 3 & - & $9^{\prime}$ & 21 & 1 & 2 \\
\hline 39 & G & NO & A. atra & n.t. & ROTA & - & - & - & - & - & - \\
\hline 40 & G & NO & Veneridae & ROTA & - & - & - & - & - & - & - \\
\hline 41 & G & SI & Veneridae & n.t. & 2 & $14,7^{\prime}$ & - & $15^{\prime}$ & 27 & 3,1 & 3 \\
\hline 42 & G & SI & Veneridae & n.t. & $5,2^{\prime}$ & $8,3^{\prime}$ & - & $11^{\prime}$ & 32 & 3,2 & 2 \\
\hline 43 & G & SI & Veneridae & n.t. & $1^{\prime}$ & $9,5^{\prime}$ & - & $13^{\prime}$ & 24 & 2,2 & 2,5 \\
\hline 44 & G & SI & Veneridae & n.t. & $4,1^{\prime}$ & $8,3^{\prime}$ & - & $11^{\prime}$ & 33 & 4,1 & 2 \\
\hline 45 & G & NO & Veneridae & ROTA & - & - & - & - & - & - & - \\
\hline 46 & G & NO & N. magellanica & n.t. & ROTA & - & - & - & - & - & - \\
\hline 47 & G & NO & N. magellanica & n.t. & $2,2^{\prime}$ & ROTA & - & - & - & - & - \\
\hline
\end{tabular}

Tabla 1. Características y tiempos de trabajo para la manufactura de cuentas C/SCI. Referencias: Exp.: experiencia, Cat.Tam.: categoría de tamaño, EFB: extracción de forma-base, PD: percusión directa, PDSY: percusión directa sobre yunque, Ab: abrasión, DPR: desgaste por rotación, D: diámetro, E: espesor, DP: diámetro de la perforación, n.t.: no tomado. Medidas expresadas en milímetros. 


\begin{tabular}{|c|c|c|c|c|c|c|c|c|c|c|c|}
\hline \multirow{3}{*}{ Exp. } & \multirow{3}{*}{$\begin{array}{l}\text { Cat. } \\
\text { Tam. }\end{array}$} & \multirow{3}{*}{ Éxito } & \multirow{3}{*}{ Taxón } & \multicolumn{4}{|c|}{ Operaciones y tiempos por técnica } & \multirow{2}{*}{\multicolumn{4}{|c|}{ Medidas }} \\
\hline & & & & \multirow{2}{*}{$\begin{array}{c}\text { EFB } \\
\text { PD }\end{array}$} & \multicolumn{2}{|c|}{ Formatización } & \multirow{2}{*}{$\begin{array}{l}\text { Perfo. } \\
\text { DPR }\end{array}$} & & & & \\
\hline & & & & & CSP & $\mathbf{A b}$ & & $\mathbf{L}$ & $\mathbf{A}$ & E & DP \\
\hline 1 & $\mathrm{P}$ & SI & N. magellanica & n.t. & $0,5^{\prime}$ & $1,4^{\prime}$ & $3^{\prime}$ & 16 & 13 & 2,3 & 2 \\
\hline 2 & $\mathrm{P}$ & SI & N. magellanica & n.t. & $0,4^{\prime}$ & $0,6^{\prime}$ & $5^{\prime}$ & 14,5 & 10,5 & 2 & 1,5 \\
\hline 3 & $\mathrm{P}$ & NO & N. magellanica & n.t. & FASC & ROTA & - & - & - & - & - \\
\hline 4 & $\mathrm{P}$ & SI & N. magellanica & n.t. & FASC & $1,2^{\prime}$ & $7^{\prime}$ & 14 & 11,5 & 3 & 2 \\
\hline 5 & $\mathrm{P}$ & SI & N. magellanica & n.t. & FASC & $1,2^{\prime}$ & $9^{\prime}$ & 17 & 12 & 2 & 3 \\
\hline 6 & $\mathrm{P}$ & SI & A. atra & n.t. & $5^{\prime}$ & $2,2^{\prime}$ & $6^{\prime}$ & 12 & 9 & 2 & 2,5 \\
\hline 7 & $\mathrm{P}$ & SI & A. atra & n.t. & $2,1^{\prime}$ & $1^{\prime}$ & $8^{\prime}$ & 14 & 10 & 2 & 3 \\
\hline 8 & $\mathrm{P}$ & SI & A. atra & n.t. & $2,2^{\prime}$ & $1^{\prime}$ & $7^{\prime}$ & 10 & 8 & 2 & 2 \\
\hline 9 & $\mathrm{P}$ & SI & A. atra & n.t. & FASC & $4,2^{\prime}$ & $9^{\prime}$ & 13 & 11 & 1,5 & 1,5 \\
\hline 10 & $P$ & SI & A. atra & n.t. & FASC & 2,3 & $6^{\prime}$ & 18 & 15 & 2 & 2 \\
\hline 11 & $\mathrm{P}$ & SI & Veneridae & n.t. & $3,5^{\prime}$ & $1,4^{\prime}$ & $15^{\prime}$ & 16 & 15 & 2 & 2 \\
\hline 12 & G & SI & N. magellanica & n.t. & $2^{\prime}$ & $1,5^{\prime}$ & $4^{\prime}$ & 29 & 24 & 2,1 & 2,5 \\
\hline 13 & G & SI & N. magellanica & n.t. & $2^{\prime}$ & $1,8^{\prime}$ & $4^{\prime}$ & 28 & 20 & 2 & 2 \\
\hline 14 & G & SI & N. magellanica & n.t. & $2^{\prime}$ & $1,4^{\prime}$ & $6^{\prime}$ & 20 & 15 & 2 & 2 \\
\hline 15 & G & SI & N. magellanica & n.t. & $1,2^{\prime}$ & $2,4^{\prime}$ & $7^{\prime}$ & 20 & 14 & 2 & 2 \\
\hline 16 & G & SI & N. magellanica & n.t. & $3,3^{\prime}$ & $3,4^{\prime}$ & $3,5^{\prime}$ & 23,2 & 20 & 3 & 3 \\
\hline 17 & G & NO & N. magellanica & n.t. & $1,3^{\prime}$ & ROTA & - & - & - & - & - \\
\hline 18 & $G$ & NO & A. atra & n.t. & ROTA & - & - & - & - & - & - \\
\hline 19 & G & NO & A. atra & n.t. & ROTA & - & - & - & - & - & - \\
\hline 20 & G & SI & A. atra & n.t. & $4,2^{\prime}$ & $6,4^{\prime}$ & $11^{\prime}$ & 26 & 23 & 2 & 2 \\
\hline 21 & G & SI & Veneridae & n.t. & $1,9^{\prime}$ & $3,1^{\prime}$ & $10^{\prime}$ & 26 & 18 & 2 & 1,5 \\
\hline
\end{tabular}

Tabla 2. Características y tiempos de trabajo para la manufactura de cuentas SCD/SR. Referencias: Exp.: experiencia, Cat.Tam.: categoría de tamaño, EFB: extracción de formabase, PD: percusión directa, CSP: corte seguido de presión, Ab: abrasión, DPR: desg aste por rotación, L: largo, A: ancho, E: espesor, DP: diámetro de la perforación, n.t.: no tomado, FASC: fragmento azarosamente subcuadrangular. Todas las medidas están expresadas en milímetros.

Extracción de la forma-base

El procedimiento consistió en golpear con el percutor lítico directamente la valva a fin de separar la charnela -o el ápice- (sectores cóncavos) y extraer las porciones más regulares y planas, útiles para elaborar cuentas (Figura 1). Esta operación no demoró más de unos segundos por valva, por ello, fue el único caso en el cual no se consignó el registro del tiempo. Durante las experiencias se comprobó que, en todos los casos, fue difícil controlar el golpe para dirigir la fractura a fin de obtener el fragmento del tamaño deseado. Las valvas de Veneridae ofrecieron mayor resistencia al golpe (hubo que ejecutar más de un impacto para lograr la fractura) que las de A. atra, mientras que las valvas de N. magellanica resultaron ser las más frágiles ante el impacto, en varios casos, astillándose en fragmentos pequeños no aptos para la elaboración de cuentas. 
Para la obtención de las formas-base de cuentas grandes, se seleccionaron sólo los ejemplares de mayor tamaño y se buscó eliminar las charnelas y ápices tratando de conservar el resto de la valva lo más entero posible. La dificultad para controlar el golpe fue crítica en estos casos, ya que en varias de las experiencias $(12,5 \%, n=3)$ impidió aprovechar la valva inicialmente seleccionada o condujo a obtener fragmentos de tamaños menores a los originalmente buscados. En el caso de las formas-base de cuentas pequeñas, el grado de control del golpe no fue un factor determinante ya que el $100 \%$ de las experiencias resultó exitosa. Incluso en los casos donde fracasó la obtención de formas-base adecuadas para la elaboración de cuentas grandes, fue posible aprovechar parte de los fragmentos generados para elaborar cuentas pequeñas. A través de este procedimiento se logró obtener entre una y dos formas-base de cuentas grandes por valva (dependiendo del tamaño de la misma), y entre cuatro y cinco fragmentos útiles para las cuentas pequeñas. Las piezas generadas poseen morfología irregular y tamaños que oscilan entre 3 y $5 \mathrm{~cm}$ y 1,5 y $2 \mathrm{~cm}$ respectivamente (Figura 2). Cabe destacar que N. magellanica resultó particularmente adecuada para la obtención de formas-base de cuentas SCD/SR grandes debido a que la disposición de sus costillas radiales facilitó las fracturas en línea recta, en varios casos, no requiriendo efectuar cortes posteriores (véase abajo).

Por último, al igual que lo observado inicialmente en Leonardt $(2013,2014)$, los desechos generados durante esta etapa consisten, principalmente, en charnelas y gran cantidad de fragmentos pequeños y astillas de valva (Figura 2). El análisis a ojo desnudo y con bajos aumentos no permitió verificar un patrón de fractura característico en los fragmentos o charnelas que permita identificarlos de manera no ambigua como resultado de la acción antrópica.

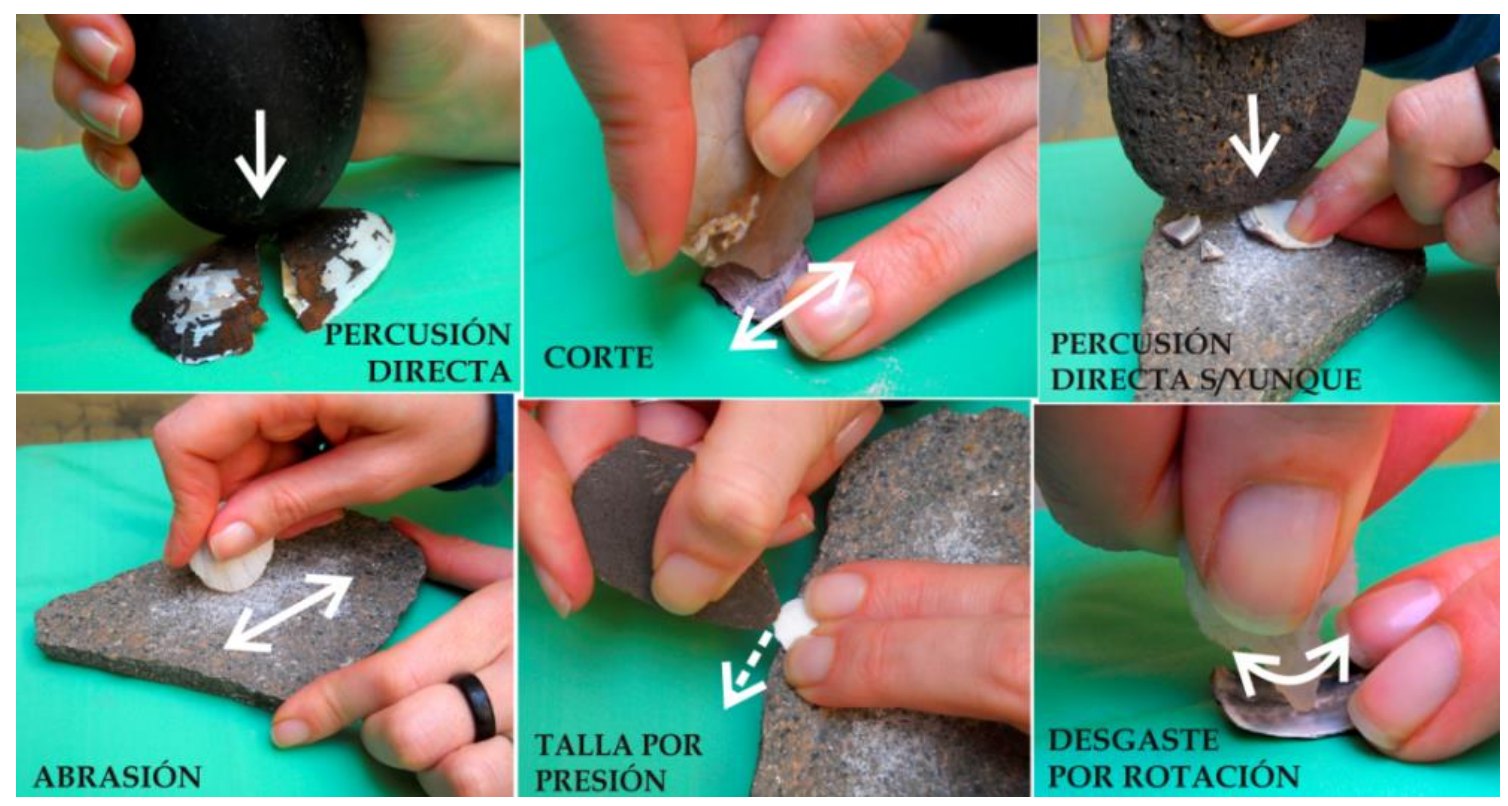

Figura 1. Técnicas de manufactura aplicadas en las distintas etapas de la experimentación. 
Formatización

\section{a. Morfologías circulares/sub-circulares}

Esta etapa se llevó a cabo siguiendo dos procedimientos. El primero de ellos tuvo por objetivo generar preformas C/SCI a partir de formas-base obtenidas en la etapa anterior y consistió en aplicación de técnica de percusión directa sobre yunque combinada con técnica de abrasión. La primera fue definida por Mayo Torné (2004) como una variante de la percusión directa y consiste en regularizar las formas-base seleccionadas a partir de ejecutar impactos con el percutor sobre los márgenes del fragmento de valva, apoyado éste sobre una roca plana, a fin de ir eliminando los sectores no deseados (Figura 1). Esta operación requirió un tiempo promedio de 2,1 minutos (desvío estándar: $1, n=25$ ) por pieza, lográndose de manera exitosa en el $83 \%$ $(n=25)$ de los casos. Una vez dada la forma inicial, el contorno de la preforma se terminó de regularizar mediante abrasión. La misma se realizó de manera individual con cada pieza a partir del desgaste del contorno con movimientos bidireccionales sobre una roca abrasiva, trabajando los fragmentos de valva de canto a la roca, en un ángulo de aproximadamente $90^{\circ}$ (Figura 1). El tiempo promedio para esta operación fue de 4,4 minutos (desvío estándar: 3,4; $\mathrm{n}=22$ ) por pieza y su porcentaje de éxito fue del 92\% ( $n=23)$. Durante estas experiencias se observó que la técnica de percusión directa sobre yunque implicó mayor riesgo que el proceso de abrasión ya que, en varios casos $(n=5)$, un mal golpe ocasionó la rotura y descarte de la pieza mientras que sólo dos preformas se rompieron durante la abrasión del contorno. Mediante la combinación de ambas técnicas se obtuvieron preformas C/SCI grandes y pequeñas con valvas de A. atra y Veneridae y preformas de tamaño pequeño con valvas de $N$. magellanica. En el caso de este último taxón, todos los intentos de obtención de preformas C/SCI grandes fracasaron (véase Tabla 1).
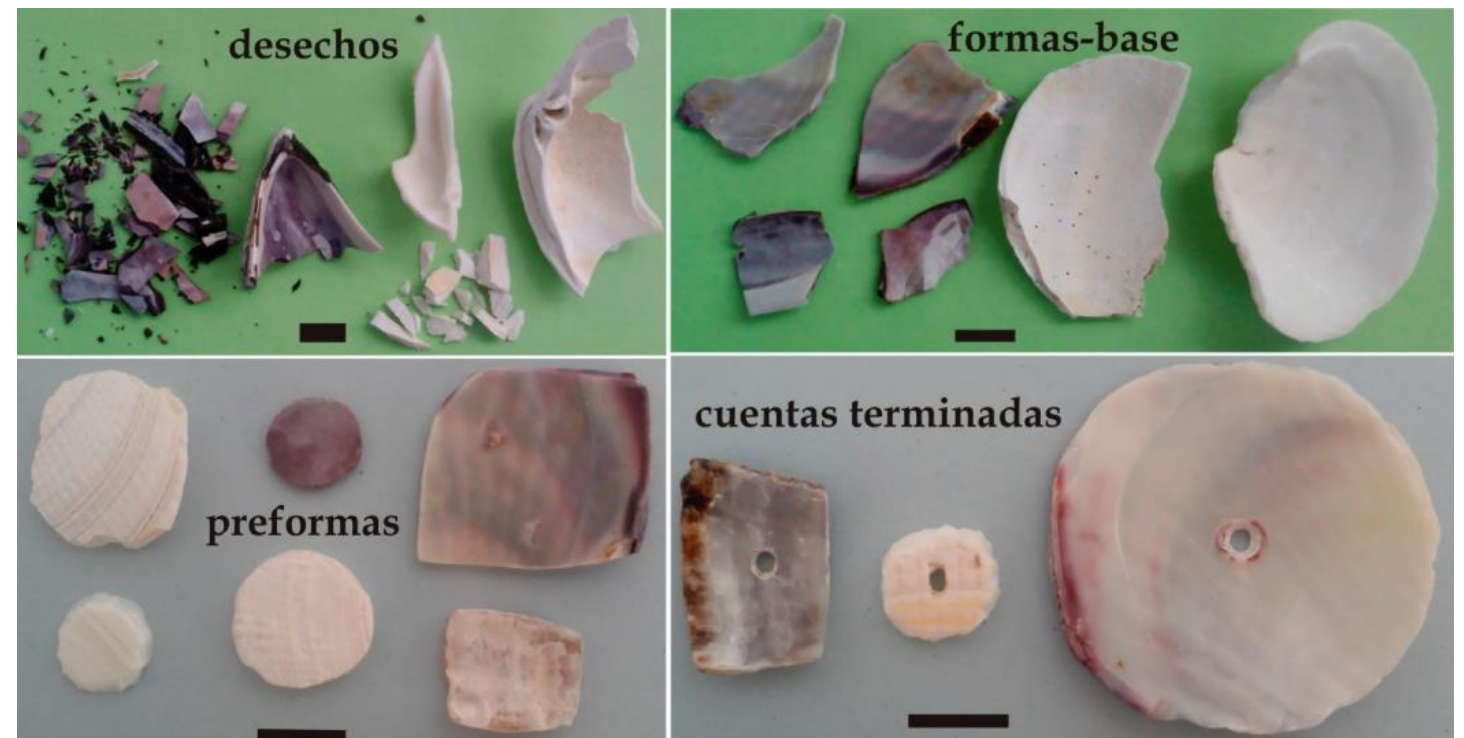

Figura 2. Desechos y subproductos generados durante la manufactura de cuentas.

Las preformas generadas mediante percusión directa sobre yunque poseen contorno poligonal con los márgenes marcados por fracturas discontinuas que se 
disponen en ángulo aproximado de $90^{\circ}$ (Figura 3 a-b). Luego, al someterlas a abrasión, el contorno se regulariza adquiriendo una forma suavizada y, en muchos casos, con presencia de estrías observables con bajos aumentos (a 10x y 20x). Las estrías producidas por el proceso de abrasión son delgadas y superficiales y se disponen de manera paralela al contorno de la pieza (véase una descripción más detallada en Leonardt 2014). Los tamaños de las preformas terminadas oscilan entre $21 \mathrm{~mm}$ y 38 $\mathrm{mm}$ en el caso de las cuentas grandes y entre $10 \mathrm{~mm}$ y $17 \mathrm{~mm}$ para las pequeñas. Los desechos de manufactura generados durante esta etapa consisten en preformas rotas durante la operación de percusión directa sobre yunque y/o durante la etapa de abrasión $\mathrm{y}$, principalmente, polvillo de valva generado durante esta última (véase también Leonardt 2014).

El segundo procedimiento consistió en la aplicación únicamente de técnica de talla por presión (Mayo y Cooke 2005) sobre formas-base de A. atra y N. magellanica, y sobre fragmentos rodados de valvas de Veneridae con la finalidad de elaborar preformas de cuentas pequeñas. Esta técnica se llevó a cabo apoyando el fragmento de valva sobre una roca, dejando sobresalir el sector del margen que se desea extraer y ejerciendo presión sobre éste con una lasca lítica espesa y aguzada hasta desprenderlo. Este procedimiento se repitió varias veces recorriendo todo el contorno del fragmento seleccionado. En todos los casos se trabajó con el fragmento de valva apoyado sobre la cara externa y ejerciendo presión desde la cara interna, en un ángulo de trabajo de aproximadamente $45^{\circ}$ (Figura 1). Mediante esta técnica sólo se pudieron conseguir preformas a partir de los fragmentos rodados de Veneridae, en un tiempo promedio de 2,6 minutos (desvío estándar: 0,6, $\mathrm{n}=6$ ) por pieza. Mientras que con las formas-base de A. atra y N. magellanica en ningún caso fue posible controlar la línea y extensión de la fractura al ejercer presión con el instrumento, con los rodados de Veneridae sólo fracasaron dos $(25 \%)$ de las ocho experiencias realizadas. Esto se debió al intento de eliminar porciones de valva demasiado grandes ó a la existencia de una distancia demasiado amplia entre el punto de presión del sector que se deseaba eliminar y la extracción anterior.

Las preformas generadas a partir de este procedimiento evidencian improntas de talla en forma de pequeñas muescas que corren de manera perpendicular y oblicua a las capas de carbonato de calcio y que son observables a ojo desnudo (Figura 3 c-d). Estas huellas se diferencian de las registradas en las preformas producidas por percusión directa sobre yunque, en tanto son más regulares entre sí y se disponen uniformemente a lo largo el contorno de la pieza. Por último, los desechos generados durante este procedimiento consisten en pequeñas astillas de valva y piezas rotas. Estas últimas suelen conservar parte del contorno con negativos de talla. 


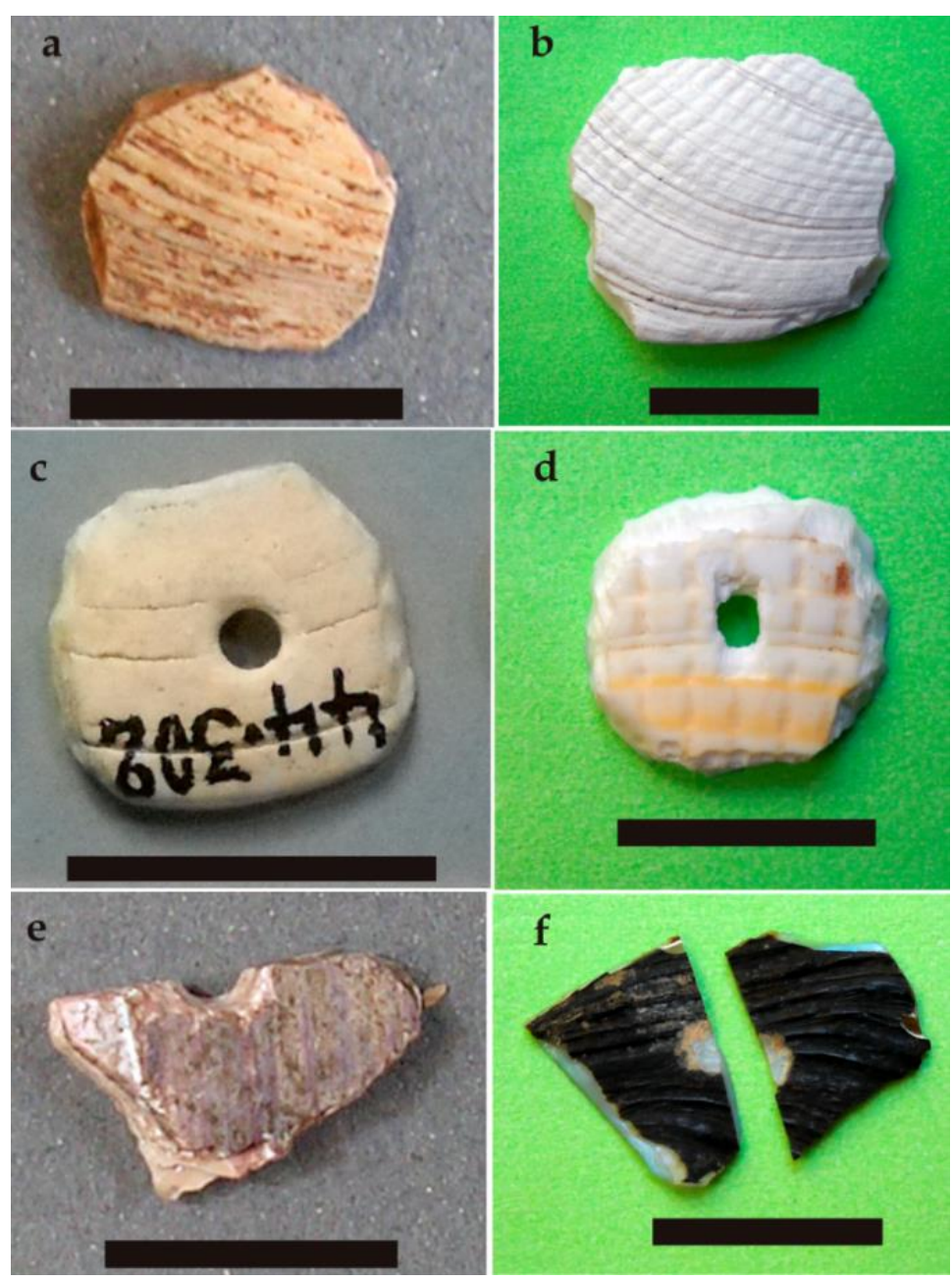

Figura3. Técnica de percusión directa sobre yunque: a) preforma arqueológica (sitio Población Anticura, Leonardt 2014), b) preforma experimental. Talla por presión: c) cuenta arqueológica del área del golfo San Matías (colección museo J. B. Ambrosetti, Leonardt 2016b), d) cuenta experimental. Pieza con perforación fracturada: e) cuenta arqueológica en proceso de elaboración rota durante perforación (Población Anticura, Leonardt 2014), f) pieza experimental sobre valva de D. chilensis rota durante perforación (Leonardt 2014).

\section{b. Morfologías sub-cuadrangulares/sub-rectangulares}

Para la elaboración de las preformas correspondientes a este tipo morfológico se aplicó técnica de corte seguido de presión, a fin de generar ángulos rectos en las formas-base seleccionadas, y técnica de abrasión destinada a regularizar el contorno de las piezas. Cabe aclarar que, en los casos en que se obtuvieron azarosamente fragmentos de ángulos rectos durante la etapa de extracción de forma-base, éstos fueron recuperados y sólo se los formatizó mediante abrasión (sin realizarles cortes).

La técnica de corte seguido de presión combina el empleo de la acción de corte, realizando movimientos bidireccionales con el instrumento activo -en un ángulo de trabajo de entre $45^{\circ}$ y $90^{\circ}$ aproximadamente- hasta producir un surco lo suficientemente profundo a partir del cual guiar el desprendimiento de un fragmento de valva mediante la aplicación de presión con un instrumento o con las manos 
(Velásquez Castro 2007) (Figura 1). El 87,5\% (n=14) de las experiencias se lograron con éxito en un tiempo promedio de 2,3 minutos por corte (desvío estándar: 1,3, n=14), realizando entre uno y dos cortes por pieza. Las preformas producidas se caracterizan por poseer ángulos rectos con al menos un perfil de corte, el cual se define por tener una inclinación menor a $90^{\circ}$ (producto de la sección en $\mathrm{V}$ que genera el corte) y conjuntos de estrías profundas, delgadas, rectas y paralelas que indican la dirección del movimiento y que son visibles a 10x y 20x (véase una descripción más detallada en Leonardt 2014). A su turno, la técnica de abrasión implicó, al igual que en el caso de las preformas C/SCI, el trabajo de los fragmentos de valva con movimientos bidireccionales en posición de canto perpendicular a la roca abrasiva (en un ángulo de trabajo de aproximadamente $90^{\circ}$, Figura 1). Esta operación se pudo realizar sin dificultad en casi todos los casos (véase Tabla 2) y demandó entre 0,6 y 6,4 minutos (promedio: 2,2', desvío estándar: 1,6, n=17), dependiendo del espesor de la valva. Cabe destacar que el proceso de abrasión implica la eliminación de los perfiles de corte, generando piezas de morfología SCD/SR y contorno suavizado (Figura 2) donde es posible observar estrías de abrasión (véase Leonardt 2014). Por último, los desechos generados durante estos procedimientos consisten en fragmentos de valva pequeños con perfiles de corte en los que conservan estrías técnicas (sólo visibles con bajos aumentos) y polvillo de valva.

Perforación

Las perforaciones de todos los tipos de cuentas se lograron con éxito, apoyando la preforma sobre una superficie plana y rotando de manera bidireccional el perforador sobre la superficie de la valva, en un ángulo de trabajo de $90^{\circ}$, hasta atravesarla por completo (Figura 1). Los orificios generados son circulares, con un diámetro promedio de 2,1 mm (desvío estándar: 0,5, n=46), poseen contorno regular y sección cónica. En su interior es posible observar, con bajos aumentos (10x), la presencia de estrías delgadas y concéntricas (véase una descripción más detallada en Leonardt 2014). El tiempo promedio requerido fue de 7,6 minutos (desvío estándar: $3, n=46$ ) por pieza y el principal desecho generado durante este procedimiento es el polvillo producido por la fricción del perforador sobre la valva.

\section{Discusión}

El programa experimental presentado se llevó a cabo siguiendo tres objetivos. Dos de ellos están muy ligados entre sí y apuntaron, por un lado, a evaluar la factibilidad de producir variedad de diseños de cuentas con distintas especies de moluscos y, por otro, a generar información empírica que permitiese conocer el grado de dificultad, tiempo y pericia técnica requeridos para su elaboración. Los resultados demuestran que es posible conseguir con éxito piezas de las distintas morfologías (C/SC y $\mathrm{SCD} / \mathrm{SR}$ ) y tamaños (grandes y pequeñas) buscados con valvas de A. atra, $N$. magellanica y Veneridae. Si bien no estuvo exenta de algunas dificultades, la cadena operativa de elaboración de estas cuentas consistió de procedimientos sencillos, cortos y repetitivos que no requirieron el manejo de un elevado nivel de destreza técnica, pudiendo ser realizados con considerable éxito por un operador poco experto (incluso 
considerando que dicho operador no comparte el contexto social donde se produjo y reprodujo esta tradición tecnológica). Esta situación, en principio, se corresponde con lo verificado previamente a partir de la elaboración de cuentas con valvas de $D$. chilensis (Leonardt 2013, 2014).

Durante el proceso productivo se observó que, la extracción de las formas-base empleando técnica de percusión directa sólo resultó riesgosa para la elaboración de cuentas grandes. Esta situación se refleja en una mayor variabilidad métrica al interior del conjunto (Tabla 3) y, en principio, podría relacionarse con el grado de pericia del artesano, en tanto un operador más experimentado podría lograr un mejor control del impacto, así como con la ineficacia de la técnica seleccionada para el procedimiento en este tipo de cuentas. A su turno, el proceso de formatización fue llevado a cabo mediante cuatro técnicas distintas (tres de ellas complementarias): percusión directa sobre yunque, talla por presión, corte seguido de presión y abrasión. Sólo las dos primeras implicaron algún tipo de dificultad. En el caso de la percusión directa sobre yunque, esta técnica permitió disminuir el tiempo invertido en la abrasión del contorno de la pieza (requiriéndose aproximadamente cinco minutos de trabajo por preforma ${ }^{2}$ contra 10 minutos si se aplica únicamente abrasión, véase Leonardt 2013). Si bien, al igual que en la percusión directa, requirió lograr cierto control del golpe para evitar que la pieza se rompa y deba descartarse, el fracaso durante su aplicación fue bajo. En cuanto a la técnica de talla por presión, aunque fue dominada con relativa facilidad en unas pocas experiencias, sólo pudo ser ejecutada con éxito en los fragmentos rodados de Veneridae. Su aplicación fracasó en todos los casos en los que se usaron fragmentos de valvas de A. atra y N. magellanica. Esto, en principio, podría estar relacionado con la estructura de dichas valvas más que con el grado de pericia del artesano. Al respecto, mientras que las valvas de venéridos están compuestas únicamente de aragonita ${ }^{3}$ (Shimamoto 1986), las valvas de mitílidos se componen por dos formas de carbonato de calcio, ambas con diferentes estructuras cristalinas y rigidez: una capa (externa y generalmente cubierta por el periostraco) de calcita y otra (interna) de aragonita, lo cual permite la generación de una interface que hace que una fractura no se propague directamente a lo largo de todo el espesor de la valva (Marin et al. 2012). Por su parte, las valvas de $N$. magellanica resultaron más frágiles que el resto de los taxones empleados y presentaron una tendencia a fracturarse siguiendo planos lineales dificultando, en consecuencia, la generación de piezas de formas circulares. Así, este es el único caso donde, sobre la base de información empírica, puede proponerse la existencia de una limitación impuesta por la materia prima.

Por último, en cuanto al proceso de perforación, aunque comúnmente ha sido caracterizado como el más sensible de toda la secuencia productiva en tanto la fractura de la pieza en esta instancia implica su descarte (Laporte 1998), todas las experiencias realizadas fueron exitosas aunque variando los tiempos de trabajo según el espesor de las valvas y el grado de desgaste del perforador. Los orificios realizados mediante esta técnica observan un importante grado de estandarización métrica (véase Tabla 3), lo cual estaría relacionado no sólo con la técnica sino también con el tipo de herramienta empleada (véase Leonardt 2016b y citas allí 
presentes). Cabe destacar que, la única consideración que se tuvo en cuenta al momento de realizar las perforaciones fue el empleo de perforadores de calcedonia o sílice ya que estos fueron los que resultaron más efectivos en experimentos previos. En este sentido, durante las experiencias de elaboración de cuentas con valvas de $D$. chilensis se intentó realizar perforaciones con lascas muy aguzadas de vidrio industrial, las cuales fracasaron debido a que el material del objeto perforante se fue rompiendo al ejercer un mínimo de presión sobre la valva (Leonardt 2013). Esta situación condujo a sugerir que no sólo es requisito que el objeto perforante tenga una dureza mayor que el objeto a perforar (en escala de Mohs: vidrio=5, calcedonia=7, valvas de moluscos=3-4) sino que también se requiere que tenga una mayor tenacidad. Así, los resultados experimentales brindan bases empíricas para suponer que la obsidiana no fue un material apto para perforar valvas de moluscos, a diferencia de lo que se ha sugerido en algunos casos por asociación de materiales en el contexto arqueológico (véase Fernández y Ramos 2008).

\begin{tabular}{|l|c|c|c|c|c|}
\hline C/SCI pequeñas (n=22) & máximo & mínimo & media & DE & recorrido \\
\hline Diám. Pieza & 17,5 & 10 & 12,7 & 2 & 7,5 \\
\hline Diám. Perforación & 3 & 1,2 & 2,1 & 0,6 & 1,8 \\
\hline C/SCI grandes (n=7) & \multicolumn{5}{|l|}{} \\
\hline Diám. Pieza & 38 & 21 & 28,7 & 5,9 & 17 \\
\hline Diám. Perforación & 3 & 1 & 2,1 & 0,6 & 2 \\
\hline SCD/SR pequeñas (n=10) & \multicolumn{5}{|l|}{} \\
\hline Largo & 18 & 10 & 14,5 & 2,4 & 8 \\
\hline Ancho & 15 & 8 & 11,3 & 2,3 & 7 \\
\hline Diám. Perforación & 3 & 1,5 & 2,2 & 0,5 & 1,5 \\
\hline SCD/SR grandes (n=7) & \multicolumn{5}{|l|}{} \\
\hline Largo & 29 & 20 & 24,6 & 3,6 & 9 \\
\hline Ancho & 24 & 14 & 19,1 & 3,8 & 10 \\
\hline Diám. Perforación & 3 & 1,5 & 2,1 & 0,5 & 1,5 \\
\hline
\end{tabular}

Tabla 3. Características métricas de las cuentas. Referencias: Diám.: diámetro, DE: desvío estándar. Todas las medidas están expresadas en milímetros.

Atendiendo a los tiempos de trabajo, se observó que la elaboración de cuentas pequeñas demandó un promedio general de 9 a 11 minutos por pieza (Tabla 4). Estos valores también se corresponden con el tiempo promedio requerido para la elaboración de las cuentas SCD/SR grandes pero no así con el de las cuentas C/SCI grandes, las cuales requirieron alrededor de 23 minutos por pieza (Tabla 4). Esto puede atribuirse a varias razones. Por un lado, dado que, en comparación con las cuentas pequeñas, las de tamaño grande poseen un perímetro mayor para regularizar, es esperable que el tiempo invertido en la abrasión del contorno sea generalmente mayor en estas últimas. En el caso de Veneridae, esto estuvo correlacionado también con su mayor espesor (véase Tabla 1). Por otro lado, el menor tiempo invertido en la elaboración de las cuentas SCD/SR grandes respecto de las C/SCI grandes está relacionado con que el 
perfil recto generado por la operación de corte seguido de presión redujo el tiempo necesario de abrasión de las piezas (véase Tablas 1 y 2)4.

\begin{tabular}{|c|c|c|c|}
\hline $\begin{array}{l}\text { Tipo de } \\
\text { cuenta }\end{array}$ & Técnica & $\begin{array}{l}\text { Tiempo } \\
\text { promedio }\end{array}$ & $\begin{array}{l}\text { Desvío } \\
\text { estándar }\end{array}$ \\
\hline \multirow{4}{*}{$\begin{array}{c}\mathrm{C} / \mathrm{SCI} \\
\text { pequeñas }\end{array}$} & PDSY & $1,7^{\prime}(n=16)$ & 0,5 \\
\hline & $\mathrm{Ab}$ & $3,1^{\prime}(n=16)$ & 1,8 \\
\hline & DPR & $7^{\prime}(n=22)$ & 2,4 \\
\hline & TPP & $2,6^{\prime}(n=6)$ & 0,6 \\
\hline \multicolumn{2}{|c|}{$\begin{array}{c}\text { Tiempo promedio } \\
\text { general }\end{array}$} & \multicolumn{2}{|c|}{$\begin{array}{c}\text { 11,8' (PDSY+Ab+DPR) y } 9,6 \\
\text { (TPP+DPR) }\end{array}$} \\
\hline \multirow{3}{*}{$\begin{array}{l}\mathrm{C} / \mathrm{SCI} \\
\text { grandes }\end{array}$} & PDSY & $2,8^{\prime}(\mathrm{n}=7)$ & 1,7 \\
\hline & $\mathrm{Ab}$ & $9,6^{\prime}(\mathrm{n}=7)$ & 6 \\
\hline & DPR & $11^{\prime}(n=7)$ & 2,4 \\
\hline \multicolumn{2}{|c|}{$\begin{array}{c}\text { Tiempo promedio } \\
\text { general }\end{array}$} & \multicolumn{2}{|c|}{$23,4^{\prime}$} \\
\hline \multirow{3}{*}{$\begin{array}{l}\mathrm{SCD} / \mathrm{SR} \\
\text { pequeñas }\end{array}$} & CSP & $2,3^{\prime}(n=6)$ & 1,2 \\
\hline & $\mathrm{Ab}$ & $1,7^{\prime}(n=10)$ & 1 \\
\hline & DPR & $7,5^{\prime}(n=10)$ & 3,2 \\
\hline \multicolumn{2}{|c|}{$\begin{array}{l}\text { Tiempo promedio } \\
\text { general }\end{array}$} & \multicolumn{2}{|c|}{$11,5^{\prime}$} \\
\hline \multirow{3}{*}{$\begin{array}{l}\text { SCD/SR } \\
\text { grandes }\end{array}$} & CSP & $2,4^{\prime}(n=7)$ & 1 \\
\hline & $\mathrm{Ab}$ & $2,9^{\prime}(n=7)$ & 1,7 \\
\hline & DPR & $6,5^{\prime}(\mathrm{n}=7)$ & 3 \\
\hline \multicolumn{2}{|c|}{$\begin{array}{l}\text { Tiempo promedio } \\
\text { general }\end{array}$} & \multicolumn{2}{|c|}{$11,8^{\prime}$} \\
\hline
\end{tabular}

Tabla 4. Tiempos promedio por técnica y cadena operativa. Nota: $\left(^{*}\right)$ no se calcularon los fragmentos azarosamente de forma subcuadrangular (FASC) ya que estos no requirieron la realización de cortes.

La información publicada relacionada con los tiempos de producción experimental de cuentas es escasa, por lo cual es difícil establecer comparaciones. Una excepción la constituyen Gurova y colaboradores (2013), quienes llevaron adelante un programa experimental orientado a evaluar la eficiencia del proceso de perforación con perforadores líticos sobre distintos materiales (minerales y orgánicos), con la finalidad de analizar las características de la producción de cuentas en el área de los montes Balcanes durante el Neolítico temprano. En dicho trabajo observan que el tiempo requerido para la elaboración de dos cuentas de morfología subcircular pequeñas con una valva de Mytilus galloprovincialis fue de 35 minutos (Gurova et al. 2013). Si bien el tiempo de elaboración requerido por cuenta es relativamente mayor (aproximadamente 17 minutos) al registrado en esta experimentación, las técnicas de formatización fueron distintas: corte de un fragmento rectangular y posterior abrasión hasta conseguir una forma redondeada. En este sentido, los tiempos registrados por los autores se asemejan a los relevados durante la experimentación con valvas de $D$. chilensis para la elaboración de cuentas C/SCI pequeñas a partir del empleo de las mismas técnicas (aproximadamente 20 minutos por cuenta, Leonardt 2013). No obstante, en la experimentación aquí presentada se pudo comprobar que la aplicación de técnica de talla por presión o percusión directa sobre yunque antes de la abrasión es 
más eficiente, en términos de tiempo invertido, para elaborar cuentas con las mismas características que las previamente elaboradas con D. chilensis (véase Leonardt 2014).

El tercer objetivo del programa experimental estuvo orientado a profundizar los conocimientos respecto de las técnicas empleadas en la elaboración de cuentas y las improntas que su aplicación deja en las valvas, a fin de generar un corpus de subproductos y desechos de manufactura plausible de ser reconocido arqueológicamente. En primer lugar, varias de las huellas técnicas definidas a partir de los resultados experimentales han podido ser identificadas y/o corroboradas en distintos conjuntos arqueológicos patagónicos. Tal es el caso de la formatización mediante talla por presión, reconocida en conjuntos procedentes de la costa del golfo San Matías (Leonardt 2016b); la identificación de técnica de percusión directa sobre yunque y abrasión en piezas del valle del río Manso inferior (Leonardt 2014), esta última también registrada en el sitio Cerro de los Indios (Santa Cruz, Leonardt et al. 2018). A esto se suma la elaboración de perforaciones mediante desgaste por rotación que ha sido confirmada en diversos conjuntos de cuentas de Patagonia (Fernández y Ramos 2008, Prates 2008, Leonardt 2014, Leonardt et al. 2018).

En segundo lugar, la experimentación realizada apoya los resultados obtenidos inicialmente con $D$. chilensis y permite sostener que la elaboración de cuentas de valva es una actividad que produce pocos desechos con posibilidad de ser reconocidos arqueológicamente (véase también Leonardt 2014). En este sentido, se observó que gran parte de las operaciones y técnicas (talla por presión, percusión directa sobre yunque, abrasión, perforación) producen, como principal desecho, polvillo y astillas de valva muy pequeñas. La operación que genera la mayor cantidad de desechos (en términos de volumen y tamaño de fragmentos) es la extracción de formas-base mediante percusión directa. Sin embargo, las charnelas y fragmentos descartados durante esta etapa no presentan un patrón de fractura singular que permita diferenciarlos de manera no ambigua de fracturas naturales. Así, los únicos desechos con potencial para ser reconocidos como tales son los fragmentos con perfiles de corte, descartados durante la aplicación de técnica de corte seguido de presión (los cuales requieren análisis con bajos aumentos para ser diagnosticados como tales), y la presencia de preformas rotas durante las etapas finales de formatización: talla del contorno, abrasión (cuyas huellas diagnósticas se observan con bajos aumentos) o perforación. Estos resultados, en principio, se ajustan a las evidencias de producción de cuentas conocidas hasta el momento en Patagonia, donde los contextos de producción se definen por el hallazgo de unas pocas piezas semiformatizadas (generalmente preformas circulares), fragmentos rotos durante el proceso de perforación o semiperforados y/o trozos de valva con estrías de abrasión (véase Fernández y Ramos 2008, Prates 2008, Leonardt 2014, Leonardt et al. 2018). Esta situación difiere de otros contextos prehispánicos de elaboración de cuentas, los cuales se caracterizan por la presencia de "talleres" donde la producción está concentrada espacialmente y definida por densas acumulaciones de artefactos, desechos y piezas en distintos estados de manufactura (véase por ejemplo Masucci 1995, Arnold y Munns 1994). Si bien para la costa norte de Chubut se propone la existencia una producción especializada de 
cuentas en momentos tardíos, en función de la gran disponibilidad de materia prima y las evidencias de aprovechamiento de moluscos en el área (Gómez Otero 2007), hasta el momento no se han registrado evidencias directas de producción de cuentas en estos sitios. Esta situación, en principio, podría deberse al hecho de que la abundante presencia de concheros en las zonas costeras (Gómez Otero 2007, Muñóz et al. 2016, entre otros) dificulta la posibilidad de analizar los fragmentos y reconocer desechos de manufactura.

\section{Conclusiones}

Como se planteó al inicio de este trabajo, evaluar la posibilidad de que las cuentas de valva hayan conformado parte de un código visual compartido a escala macroregional en Patagonia requiere, en principio, el registro arqueológico de patrones de diseño y producción de cuentas estandarizados a escala espacial amplia. Los análisis realizados hasta el momento en conjuntos arqueomalacológicos procedentes de distintos contextos y áreas de Patagonia permiten sugerir que esta situación se cumple para las cuentas de tipo circular/subcircular pequeñas, las cuales presentan un patrón métrico-morfológico fuertemente estandarizado (Leonardt 2017). Ante esta situación, el primer interrogante que surge al respecto es en qué medida, el predominio de un tipo morfométrico particular de cuentas es resultado de las elecciones hechas por los artesanos en función de cánones sociales, o corresponde a la existencia de condicionantes de índole práctica que restringen o subordinan las posibilidades de producción de estos artefactos a determinadas formas y tamaños. En este sentido, a través de programa experimental llevado a cabo es posible sugerir que no existen limitaciones importantes en términos de las propiedades de las materias primas (independientemente del costo que pueda estar implicado en su obtención), herramientas y técnicas empleadas para elaborar distintos diseños de cuentas como las aquí presentadas. Por el contrario, es posible sostener que la elaboración de cuentas no requiere un grado de habilidad técnica o know-how elevado para llevar a cabo la complejidad de la tarea o el manejo de artefactos especializados ${ }^{5}$ sino que la misma puede ser llevada a cabo con éxito por un operador poco experto. Esta situación, en principio, apoya la condición de replicabilidad que requiere el código (en este caso las cuentas como unidades mínimas de comunicación) para ser compartido a escala amplia y favorece la posibilidad de dispersión de esta tecnología a través de la circulación de conocimientos y/o la imitación (Apel 2008, Stiner 2014) ${ }^{6}$. En tal sentido, la amplia distribución de las valvas de moluscos marinos en el interior de Patagonia (Zubimendi 2010), la identificación de distintas situaciones de elaboración local de cuentas (Prates 2008, Leonardt 2014), el registro predominante de cuentas de valva por sobre otro tipo de materias primas (p. ej. roca, hueso, Leonardt 2016a) y la variedad de artefactos elaborados con cuentas hallados en distintos contextos mortuorios (p. ej. Vignati 1944, Gómez Otero 2007) informa respecto de la importante carga simbólica que estos elementos pudieron tener en el pasado.

Agradecimientos: Este trabajo se enmarca en un proyecto de investigación doctoral que fue llevado a cabo gracias al apoyo y dirección de Vivian Scheinsohn, Pablo Fernández 
e Isabel Cruz y al financiamiento de una Beca Doctoral Interna de CONICET. Se extiende el agradecimiento a los dos evaluadores anónimos por sus valiosos comentarios que han sido de gran aporte para mejorar este trabajo.

\section{Notas}

1. En todos los casos se recolectó valvas que no presentaron un intenso estado de deterioro.

2. El tiempo se calculó sumando el tiempo promedio requerido para la percusión directa sobre yunque y el requerido para la abrasión del contorno.

3. Aragonita y calcita constituyen distintas formas cristalinas del carbonato de calcio. Esto se conoce como polimorfismo mineral, en tanto ambos minerales tienen idéntica composición química pero diferente estructura cristalina.

4. Promedio de 2,9 minutos $(n=7)$ en el caso de las SCD/SR grandes y de 9,5 minutos $(n=7)$ en el caso de las C/SCI grandes.

5. Los perforadores líticos fueron los artefactos empleados durante la elaboración experimental de cuentas con mayor inversión de tiempo y complejidad en su elaboración. No obstante, no hay certezas hasta el momento que su uso haya sido exclusivo para la elaboración de cuentas.

6. Al respecto, cabe aclarar que el hecho de que el código pueda ser fácilmente replicable no implica que cualquier persona dentro de una sociedad esté culturalmente habilitada para producir cuentas de valva, ya que el valor social de un objeto puede estar determinado por distintas propiedades que exceden a la habilidad o tiempo requerido para elaborarlo (véase Spielman 2002, Gómez Gastélum 2010).

\section{Bibliografía citada}

Álvarez Fernández, E.

2006 Los objetos de adorno-colgantes del paleolítico superior y del mesolítico en la Cornisa Cantábrica y en el valle del Ebro: una visión europea. Universidad de Salamanca, Salamanca.

Apel, J.

2008 Knowledge, know-how and raw material. The production of Late Neolithic flint daggers in Scandinavia. Journal of Archaeological Method and Theory 15 (1): 91-111.

Arnold, J. E. y A. Munns

1994 Independent or Attached Specialization: The Organization of Shell Bead Production in California. Journal of Field Archaeology 21(4): 473-489.

Berón, M., R. M. Di Donato y A. Markán

2012 Leather funerary packages: Mortuary practices and differential preservation in a Late Holocene prehispanic cemetery (Pampean region, Argentina). Quaternary International 258: 51-62.

Binford, L. R.

1981 Bones. Ancient Men and Modern Myths. Academic Press, San Diego.

Cardillo, M. y F. Borella

2017 Caracterización métrica y morfológica de las cuentas provenientes del área costera norpatagónica. Río Negro, Argentina. Arqueología 23 (2): 81-97. 
Cassiodoro, G.

2005 Tecnología malacológica de los entierros humanos del lago Salitroso (Santa Cruz, Argentina). Relaciones de la Sociedad Argentina de Antropología 30: 257-262.

Cassiodoro, G. y S. García Guraieb

2009 Análisis del registro tecnológico y osteológico de los entierros humanos del Holoceno tardío del lago Salitroso (Santa Cruz): un aporte al estudio del comportamiento mortuorio de cazadores-recolectores. Arqueología de la Patagonia. Una mirada desde el último confín (ed. por M. Salemme, F. Santiago, M. Álvarez, E. Piana, M. Vázquez y M. E. Mansur), pp. 613-628. Editorial Utopías, Ushuaia.

Cimimo, A.

2007 Arqueomalacología en las sierras de la vida: análisis de los adornos realizados sobre materia prima malacológica hallados en el sitio Chenque I (P.N.L.C., provincia de La Pampa). Arqueología de las Pampas Tomo I. (ed. por C. Bayón, A. Pupio, M. I. González, N. Flegenheimer y M. Frère), pp. 309-324. Sociedad Argentina de Antropología, Buenos Aires.

Cimino, A., M. Guastavino y S. Velardez

2004 ¡Cuantas cuentas..! Elementos de adorno del sitio Chenque 1, Parque Nacional Lihue Calel, provincia de La Pampa. Aproximaciones contemporáneas a la arqueología pampeana. Perspectivas teóricas, metodológicas, analíticas y casos de estudio (ed. por G. Martínez, M. Gutierrez, R. Curtoni, M Berón y P. Madrid), pp. 259-273. Universidad Nacional del Centro de la Provincia de Buenos Aires, Olavarría.

Della Negra, C. E. y V. Ibáñez Saint Paul

2012 Adornos personales de Aquihuecó (Neuquén, Patagonia norte). Atek-Na 2: 14-32.

Fernández, M. y M. Ramos

2008 Hallazgos especiales del sitio Casa de Piedra de Ortega (Pcia. de Río Negro): producción, funcionalidad y tendencias temporales. Rastros. Arqueología e historia de la cuenca del río Limay. Serie monográfica, vol. 2.

Eco, U.

[1968] 1986. La estructura ausente: Introducción a la semiótica. Barcelona, Lumen.

Gómez Gastélum, L.

2010 El simbolismo de las conchas marinas en el antiguo occidente de México durante el Clásico y el Post Clásico Temprano. Ecos del Pasado. Los moluscos Arqueológicos en México (coord. por L. Suárez Diez y A. Velázquez Castro), pp. 311-333. INAH, México.

Gómez Otero, J.

2007 Dieta, uso del espacio y evolución en poblaciones cazadoras -recolectoras de la costa centro- septentrional de Patagonia durante el Holoceno medio y tardío. Tesis Doctoral. Facultad de Filosofía y Letras, UBA. Buenos Aires.

Graeber, D.

1996 Beads and Money: Notes toward a Theory of Wealth and Power. American Ethnologist 23(1): 4-24.

Gurova, M., C. Bonsall, B. Bradley y E. Anastassova

2013 Approaching prehistoric skills: experimental drilling in the context of bead manufacturing. Bulgarian e-Journal of Archaeology 3: 201-221. 
Kuhn, S. L. y M. C. Stiner

2007 Body ornamentation as information technology: towards an understanding of the significance of early beads. Rethinking the human revolution: new behavioural and biological perspectives on the origin and dispersal of modern humans (ed. por P. Mellars, K. Boyle, O. Bar-Yosef y C. Stiner), pp. 45-54. McDonald Institute for Archaeological Research, Cambridge.

Laporte, L.

1998 Ornaments production centres along the french atlantic coast during the late Neolithic. Craft specialization: operational sequences and beyond, Papers from the EEA third Annual Meeting at Rabean (ed. por S. Milliken y M. Vidale), pp. 17-23. BAR International Series 720, Oxford.

Laporte, L., N. Desse-Berset, Y. Gruet y A. Tresset

1994 Un lieu de fabrication de parure au Néolithique Final et économie de subsístanse. Le site de Ponthezières à Saint-Georges-d'Oléron (Charente-Maritime). Le Néolithique du centre-ouest de la France. Actes du XXI colloque inter-régional sur le Néolithique, pp. 237255. Poitiers.

Lemonnier, $\mathrm{P}$.

1986 The study of material culture today: toward an anthropology of technical systems. Journal of Anthropological Archaeology 5: 147-186.

Leonardt, $\mathrm{S}$.

2013 Artefactos malacológicos en el bosque y ecotono bosque - estepa del Noroeste de Patagonia. Tesis de Licenciatura, Facultad de Filosofía y Letras, UBA. Buenos Aires.

2014 Producción local de cuentas de valva en el bosque del Noroeste de Patagonia. Una aproximación desde la arqueología experimental. Relaciones de la Sociedad Argentina de Antropología 39 (2): 463-482.

2016a Variabilidad temporal en la producción de artefactos de adorno personal en Patagonia continental: análisis a partir del sitio Población Anticura (provincia de Río Negro, Argentina). Magallania 44 (1): 229-247.

2016b Análisis tecno-morfológico de cuentas de valva procedentes de Patagonia norte: colección Museo Etnográfico Juan Bautista Ambrosetti. La Zaranda de Ideas 14(1): 9-24.

2017 Producción y distribución de cuentas de valva en el Holoceno tardio de Patagonia continental argentina. Tesis de Doctorado, Facultad de Filosofía y Letras, UBA. Buenos Aires.

Leonardt, S., M. J. Figuerero Torres y G. L. Mengoni Goñalons

2018 El empleo de valvas de moluscos para la elaboración de cuentas en Cerro de los Indios 1 (provincia de Santa Cruz, Argentina). Póster presentado en el IV Encuentro Latinoamericano de Zooarqueología, 21 a 23 de noviembre de 2018. Río Gallegos, Santa Cruz.

Marin, F., N. Le Roy y B. Marie

2012 The formation and mineralization of mollusk shell. Frontiers in Bioscience 4: 10991125.

Masucci, M. A.

1995 Marine shell bead production and the role of domestic craft activities in the economy of the Guangala Phase, Southwest Ecuador. Latin American Antiquity 6(1): 7084 . 
Mayo Torné, J.

2004 La Industria Prehispánica de Conchas Marinas en "Gran Coclé", Panamá. Disponible online en http://striweb.si.edu/cooke/tesis/industria_conchas_cocle.html.

Mayo, J. y R. Cooke

2005 La industria prehispánica de conchas marinas en Gran Coclé, Panamá. Análisis tecnológico de los artefactos de concha del basurero-taller del Sitio Cerro Juan Díaz, Los Santos, Panamá. Archaeofauna 14: 285-298.

Muñoz, A. S., M. S. Caracotche e I. Cruz

2009 Cronología de la costa al sur del río Santa Cruz: nuevas dataciones radiocarbónicas en Punta Entrada y Parque Nacional Monte León (provincia de Santa Cruz, Argentina). Magallania 37(1):19-38.

Palacios, O. A.

2008 La Cueva Epullán Grande, Pcia. del Neuquén. Análisis de los artefactos líticos del Período Tardío (1100 AP - contacto). Runa 29: 53-77.

Prates, L.

2008 Los indígenas del río Negro. Un enfoque arqueológico. Sociedad Argentina de Antropología, Buenos Aires.

Shannon, C. E. y W. Weaver

1964 The mathematical theory of communication. University o Illinois Press, Urbana.

Shimamoto, M.

1986 Shell microstructure of the Veneridae (Bivalvia) and its phylogenetic implications. Scientific Reports of the Tohoku University, Second Series, Geology 56(1): 1-39.

Silveira, M., L. López y G. Pastorino

2010 Movilidad, redes de intercambio y circulación de bienes en el sudoeste del Neuquén (Norpatagonia, Argentina). Los moluscos marinos del lago Traful. Intersecciones en Antropología 11: 227-236.

Spielman, K. A.

2002 Feasting, Craft Specialization, and the Ritual Mode of Production in Small-Scale Societies. American Anthropologist 104(1): 195-207.

Suárez Diez, L.

2002 [1975] Tipología de los objetos prehispánicos de concha. Instituto Nacional de Antropología e Historia, México.

Stiner, M. C.

2014 Finding a Common Bandwidth: Causes of Convergence and Diversity in Paleolithic Beads. Biological Theory 9 (1): 51-64.

Velázquez Castro, A.

2007 La producción especializada de los objetos de concha del Templo Mayor de Tenochtitlan. Instituto Nacional de Antropología e Historia, México. 
Vignati, M. A.

1944 Antigüedades en la región de los lagos Nahuel Huapi y Traful (I-VII). Notas del Museo de La Plata, sección Antropología 23 (IX): 53-165.

Wiessner, $\mathrm{P}$.

1984 Reconsidering the behavioral basis for style: a case study among the Kalahari San. Journal of Anthropological Archaeology 3: 190-234.

Wobst, M.

1977 Stylistic behavior and information exchange. Papers for the Director: Research Essays in Honor of James B. Griffin, Anthropological Papers 61 (ed. por C. E. Cleland), pp. 317-342. University of Michigan, Ann Arbor.

Zubimendi, M. A.

2010 Malacological artifacts in Argentine Patagonia. Munibe. Suplemento: 262-270.

$2008 \mathrm{El}$ uso de moluscos con fines alimenticios y utilitarios en la prehistoria patagónica. Segundas Jornadas de Arqueología y Paleontología, pp. 44-63, Pico Truncado.

2015 Síntesis historiográfica de las investigaciones sobre artefacto arqueomalacológicos de la Patagonia Continental Argentina (1867-2011). Arqueomalacología. Abordajes metodológicos y casos de estudio en Cono Sur (ed. por H. Hammond y M. A. Zubimendi), pp. 217-253. Fundación de Historia Natural Félix de Azara, Buenos Aires.

Zubimendi, M. A. y P. Ambrústolo

2011 La presencia de ítems marinos en el interior de Patagonia Central. Movilidad y migraciones. Actas de las III Jornadas Multidisciplinarias (ed. por A. Guiance), pp. 291-305. Dunken, Buenos Aires. 